\title{
Interspecies Reconstructed Embryonic Cell Interaction between Campbell Hamster (Phodopus campbelli) and Mice (Mus musculus)
}

\author{
Noer Muhammad Dliyaul Haq', Diah Pristihadi', Vista Budiariati', Dwi Budiono', Al Mukhlas Fikri', Mokhamad \\ Fahrudin', Cece Sumantri' ${ }^{2}$, Arief Boediono ${ }^{1 *}$ \\ ${ }^{1}$ Department of Anatomy, Physiology and Pharmacology, Faculty of Veterinary Medicine, IPB University, Bogor, Indonesia \\ ${ }^{2}$ Department of Animal Production and Technology, Faculty of Animal Science, IPB University, Bogor, Indonesia \\ ${ }^{3}$ Departement of Community Nutrition, Faculty of Human Ecology, IPB University, Bogor, Indonesia
}

\section{ARTICLE INFO}

\section{Article history:}

Received July 19, 2020

Received in revised form March 17, 2021

Accepted April 28, 2021

\section{KEYWORDS:}

Inner cell mass (ICM),

Interspecies embryo reconstruction,

Mus musculus,

Non-surgical embryo transfer,

Phodopus campbelli

\begin{abstract}
Interspecies embryo transfer is a seldom-used method to increase the successful conservation of endangered species. The study aimed to determine the potential development of interspecies reconstructed embryos. The present study used two animal models, Campbell hamsters (Phodopus campbelli) and mice (Mus musculus). The isolated inner cell mass (ICM) of hamster embryos were injected into the mice embryos. The embryos were transferred to the pseudopregnant mice using non-surgery embryos transfer methods. The fetuses were collected at day 13.5 of gestation for morphometric measurement and cytochrome b (Cyt b) analysis which used to determine the species of obtained fetuses. The results showed that the viability, pregnancy rate, and embryonic implantation ability of the interpecies reconstructed embryos did not differ significantly $(p>0.05)$ compared to non-reconstructed embryos. Morphometric measurement showed that the crown-rump (CR) and the weight of fetuses in the reconstructed group were significantly higher than non-reconstructed group $(p<0.05)$. According to $C y t b$ analysis, the species of obtained fetuses were mice, while the population of hamster cells were found only in the blighted ovum (resorption). Therefore, it can be concluded that interspecies reconstructed embryos are able to implant. However, the population of mice cells are only found to develop.
\end{abstract}

\section{Introduction}

Interspecies embryo transfer is one of several methods developed by researchers to support the conservation of endangered species. However, the efficiency of interspecies embryos transfer in the mammals is still low due to the maternal immune response during the process of embryo implantation. The immunological communication between the maternal and embryo influences the success of implantation and fetal development. Several approaches have been taken to improve the success of interspecies embryo transfer including interspecies embryo reconstruction (Amstislavsky 2006; Rapacz-Leopard et al. 2014).

Interspecies embryo reconstruction can be performed by either cell microinjection or interspecies

\footnotetext{
* Corresponding Author

E-mail Address: ab@apps.ipb.ac.id
}

somatic cell nuclear transfer (iSCNT). In general, those methods are used to investigate the development of cells. The previous study showed that the cytoplasm of the sheep was able to support the development of the Argali nucleus (Ovis Ammon) until at the blastocyst stage (Pan et al. 2013). Thus, the nucleus transfer technique was hypothesized to be the promising method in the conservation, especially on the Argali species (Ovis ammon). Nevertheless, the weaknesses of this method include a long process and requiring high level of skill to support the success of iSCNT. In addition, the optimization of donor cells preparation and the accuracy of the microinjection position of donor cells are the common challenge in iSCNT (Fatira et al. 2018). Another method currently being developed for the interspecies embryo reconstruction is cell microinjection which usually carried out to obtain chimera embryos.

Cell microinjection methods are performed by collecting ICM from donor blastocyst or naïve cells 
which are subsequently injected into the recipient blastocyst. Naïve cells are able to develop after injection into the recipient blastocyst (Huang et al. 2018). In addition, the development of these cells will result in the formation of interspecies chimera. Chimera is a merging of two or more cell populations from different embryos into one individual. However, the information of contribution and distribution of donor cells in the chimera individual is still limited. Therefore, several researchers conducted a combination of chimera methods with gene editing to force the donor cells to differentiate into certain organs (Huang et al. 2018; Freedman 2018; Garry and Garry 2019).

The previous study found that intergenus chimera embryos from goats (Capra hircus) and sheep (Ovis Aries) were able to develop until birth (Fehilly et al. 1984). In addition, other study tried to perform the intergenus chimera embryos from mice and rats (Bozyk et al. 2017). The results showed that the embryos were able to develop and be born. However, the embryo reconstruction of sheep-goat and micerat differ at the genus level. There has not been study to investigate the development of reconstructed embryos from two different species at the family level. Thus, this study was conducted to determine the potential development of interspecies reconstructed embryos from hamster (Phodopus campbelli) and mice (Mus musculus) which differ at family level. These animals have the similarities in size, gestation period, the speed of cell development and type of implantation (Reese et al. 2008). We expected the reconstructed embryos could be transferred into the mice. In addition, ICM hamster as donor cells were able to develop without any mixture with cells from mice as recipient.

\section{Materials and Methods}

\subsection{Material and Media}

Campbell hamster (Phodopus campbelli) and mice (Mus musculus) were used as donor and recipient embryos, respectively. The female hamster and mice aged 3 months and 1 month, respectively. The animals were kept at a temperature of $22-25^{\circ} \mathrm{C}$ and under 12:12 light: dark cycles. The feed and drink were provided ad libitum. The all experimental procedures has been approved by the Animal Ethics Committee of the Faculty of Veterinary Medicine, IPB University (No. 121/KEH/SKE/IV/2019).
The present study used several materials including pregnant mare serum gonadotrophin (PMSG) (Folligon, Intervet, Netherldan), human chorionic gonadotrophin (HCG) (Chorulon, Intervet, Netherldan), GMOP (Vitrolife, Sweden), G2 culture medium (Vitrolife, Sweden), Hoechst 33342 (Invitrogen), needle (OD $20 \mu \mathrm{m}$ ), holding (OD $50 \mu \mathrm{m}$ ), I.V. catether pen type 26G (GEA medical), modified speculum.

\subsection{Method of Superovulation and Collection of Embryos In Vivo}

The superovulation in the female hamster was induced by 5 IU PMSG and 10 IU hCG (50-57 h intervals), while female mice were induced by $5 \mathrm{IU}$ PMSG and 5 IU hCG ( $48 \mathrm{~h}$ intervals). Furthermore, the superovulated females were mated with the male (1:1). The embryos were collected at day 4 postcoitus following the procedures by Nagy et al. 2003 . The collected embryos were then transferred to the handling medium of GMOP $+5 \%$ serum.

\subsection{Production of Interspecies Reconstructed Embryos}

The production of interspecies reconstructed embryos were performed by isolating the inner cell mass (ICM) from hamster embryos at the blastocyst stage. The isolation was carried out using the immunosurgery method referring to the procedure has been previously reported (MataHine et al. 2008). The isolated ICM was injected into mice embryo at the blastocyst stage following the procedures reported by Boediono et al. (2006) using micromanipulator microscope (Olympus IX70) and piezo (Prime Tech). The recontructed embryos were cultured in a G2 medium for $10 \mathrm{~h}$ for further analysis. Furthermore, the observation of embryo viability was done based on the morphology and the ability of embryo reexpansion.

\subsection{Viability Donor Cell Analysis}

The viability analysis was randomly performed on reconstructed embryos using Hoechst 33342 (Invitrogen) staining. The ICM hamster obtained from the immmunosurgery was incubated in a 100 $\mu \mathrm{g} / \mathrm{ml}$ Hoechst dye for $10 \mathrm{~min}$. Furthermore, the embryo was reconstructed and cultured for $10 \mathrm{~h}$. The living reconstructed embryos were observed under the flouresense microscope at 350/461 nm. 


\subsection{Embryo Transfer}

Embryos transfer was conducted by non-surgery method on mice as a recipient. Embryo transfer was done at day 3.5 day after mating indicated by vaginal plug. The tools used in the embryo transfer were a modification of tools developed by Green et al. (2009). Speculum was made from a $500 \mathrm{ml}$ microtip with a length of $1.2 \mathrm{~cm}$; OD front $0.14 \mathrm{~cm}$ and $O D$ rear $0.26 \mathrm{~cm}$. Transfer pipette was I.V. catheter pen type 26G (GEA medical); 19 mm (Figure 1).

The embryo transfer was started by collecting around 10-15 of interspecies reconstructed embryos in a culture medium drop. The recontructed embryos were subsequently inserted into the transfer pipette that used to send the embryos from the culture medium to the the recipients. The recipients were kept and euthanized at day 13.5.

\subsection{Fetus Collection and Morphometric Measurement}

The fetuses and placentas were collectted following the procedure performed by Nagy et al. (2003). Fetus and placenta were subsequently separated and weighed. Morphometric variables (crown rump, weight, diameter, and area of placenta) were analyzed using the Image J 1.52a software.

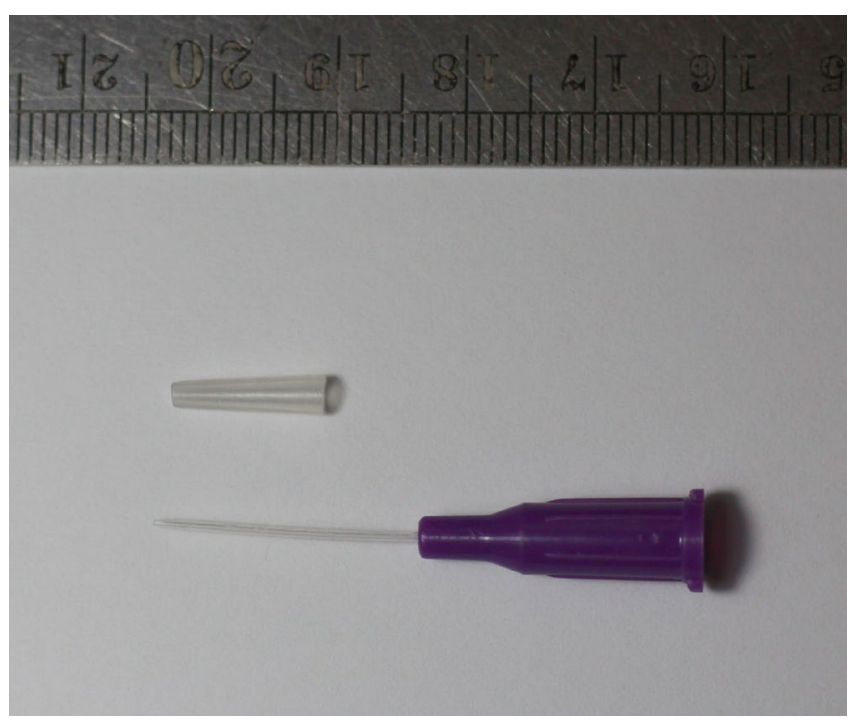

Figure 1. Tools of non-surgery embryo transfer

\subsection{Species Identification}

The species of fetuses was identified using $C y t b$ analysis by following the procedure by Nuraini et al. (2012). Cytb primers were designed using specific software for mice and hamster from NCBI database (Table 1). Amplification was run on geneAmp PCR system 9700 (Applied Biosystem TM) with denaturation condition started at $94^{\circ} \mathrm{C}$ for $5 \mathrm{~min}, 35$ cycles of denaturation at $94^{\circ} \mathrm{C}$ for $45 \mathrm{sec}$, annaeling at $60^{\circ} \mathrm{C}$ for $45 \mathrm{sec}$ and elongation at $72^{\circ} \mathrm{C}$ for $1 \mathrm{~min}$, and the final elongation at $72^{\circ} \mathrm{C}$ for $5 \mathrm{~min}$.

\subsection{Statistical Analysis}

Data were analysed using SPSS 25 software. Statistical tests were performed using the MannWhiteney test for non-parametric data and independent t-tests for parametric data.

\section{Results}

The morphological analysis showed that the reconstructed embryos were able to survive characterized by the ability of the embryo to reexpand (Figure 2). The viability of reconstructed embryos did not differ significantly compared to the non-reconstructed embryos ( $p>0.05$ ) (Table 2). After embryo reconstructed culture, we found that the embryos mostly contained 2 ICMs (84.31\%), while embryos with 1 ICM were only $15.69 \%$. In addition, the viability analysis of the donor ICM using Hoechst staining showed that these cells were able to survive for $10 \mathrm{~h}$ post-reconstruction characterized by the colour using flourescence observation (Figure 3).

After collection, the reconstructed embryos were able to implant indicated by the the development of fetuses. However, the present study also found the blighted ovum (resorption) (Table 3 ). The obtained fetus and placenta can be seen in Figure 4. The morphometric analysis indicated that the length of the crown-rump (CR) and weight of fetuses in the reconstructed group were significantly higher than the non-reconstruced group $(\mathrm{p}<0.05)$ (Table 4). Nevertheless, the weights, diameters, and area of placentas and blighted ovum (resorption) did

Table 1. Specific genes primer

\begin{tabular}{llllc}
\hline Primer & & Access number & Sequence & Length product (bp) \\
\hline Cytb & $\mathrm{F}$ & & 5'-GACTCATCCGCTATCTACAC-‘3 & 308 \\
(hamster) & $\mathrm{R}$ & KT626637.1 & 5'-GAAGATCGTGTGAGTGTGG-'3 & \\
Cytb & $\mathrm{F}$ & & 5'-CTACTGTTCGCAGTCATAGC-'3 & 419 \\
(mencit) & $\mathrm{R}$ & HM222709.1 & 5'-GGTATGTAGTTGTCTGGGTC-3 & 4 \\
\hline
\end{tabular}



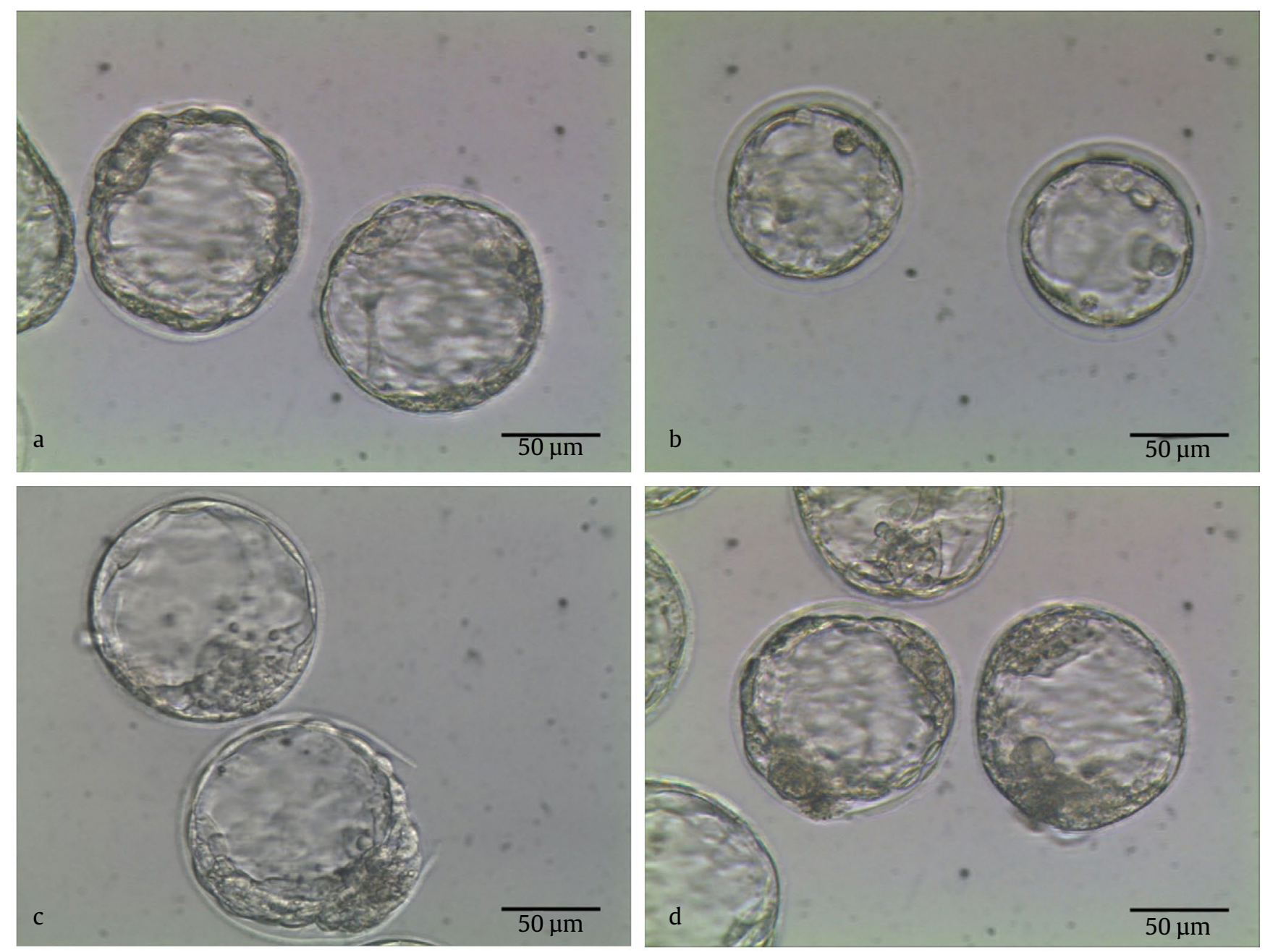

Figure 2. Production of embryos reconstructed. (a) Mice embryos at blastocyst stage, (b) hamster embryos at blastocyst stage, (c) interspecies reconstructed embryos with one ICM, (d) interspecies reconstructed embryos with 2 ICM. Scale bar: $50 \mu \mathrm{m}$

Table 2. Viability of embryos reconstruction

\begin{tabular}{lcccc}
\hline Group & Viability $(\%)$ & 0 ICM $(\%)$ & 1 ICM (\%) & 2 ICM (\%) \\
\hline Normal embryos & $50 / 50$ & $0 / 50$ & $50 / 50$ & $(0 / 50)$ \\
$(\mathrm{n}=50)$ & $(100)$ & $(0)$ & $(100)$ & 0 \\
Reconstructed & $51 / 54$ & $0 / 81$ & $8 / 51$ & $43 / 51$ \\
embryos $(\mathrm{n}=54)$ & $(94.23)$ & $(0)$ & $(15.69)$ & $(84.31)$ \\
\hline
\end{tabular}
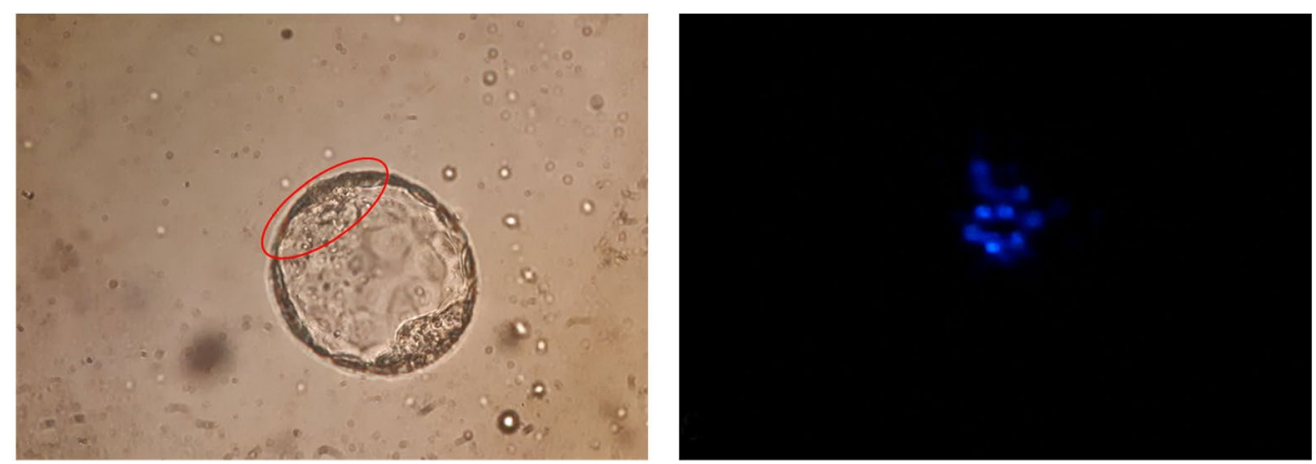

Figure 3. ICM donor in interspecies reconstructed embryo 
Table 3. The ability to implant of reconstructed embryos

\begin{tabular}{lcllll}
\hline Gruop & Number of recipient & $\begin{array}{l}\text { Pregnancy } \\
\text { rate }(\%)^{*}\end{array}$ & $\begin{array}{l}\text { Implantation } \\
\text { rate }(\%)^{*}\end{array}$ & Fetuses (\%)* & $\begin{array}{l}\text { Blighted ovum } \\
\text { (Resorption) }(\%)^{*}\end{array}$ \\
\hline Normal embryos $(\mathrm{n}=81)$ & 6 & $5 / 6$ & $36 / 81$ & $8 / 81$ & $38 / 81$ \\
& & $(83.33)$ & $\begin{array}{l}(45.56 \pm 11.26) \\
(8.06 \pm 5.28)\end{array}$ & $\begin{array}{l}(56.76 \pm 16.85) \\
15 / 51\end{array}$ \\
Reconstructed embryos $(\mathrm{n}=51)$ & 5 & $3 / 5$ & 151 & $7 / 51$ & $15 / 51$ \\
& & $(60)$ & $(24.96 \pm 12.81)$ & $(11.58 \pm 7.08)$ & $(28.93 \pm 16.26)$ \\
\hline
\end{tabular}

*Pregnancy rate (\%) is pregnancy success divided by the number of recipients the embryo transfers; Implantation rate (\%) is the total number of implantation points found divided by the total number of embryos transferred; Fetuses (\%) is the number of fetuses found divided by the total number of embryos transferred; Blighted ovum (\%) is the number of placenta without fetus found divided by the total number of embryos transferred

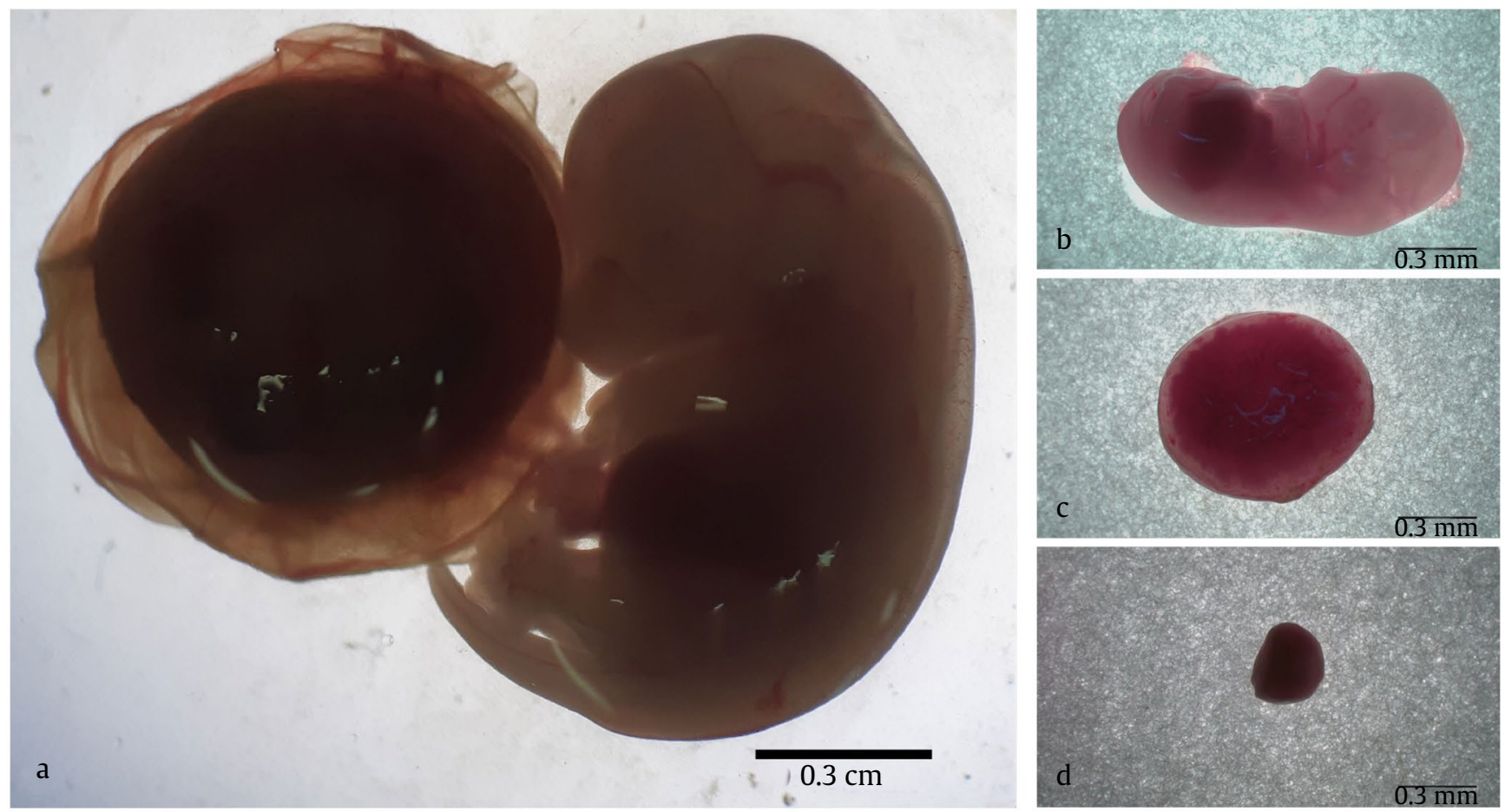

Figure 4. Fetal collection after embryo reconstruction transfer. (a) Fetal at 13.5 days gestational, (b) Fetus, (c) Placenta, (d) blighted ovum (resorption). Bar scale: $0.3 \mathrm{~cm}$

not differ significantly among both groups ( $>>0.05)$ (Table 5).

The Cytb analysis was done on the collected fetuses, placentas and blighted ovum. The cytb analysis showed that the developed fetuses and its placentas have one band with a length of amplification product of $419 \mathrm{bp}$. Based on this result, it can be concluded that developed fetuses and its placenta have only one cell population derived from the mice species. However, a total of $0.07 \%(1 / 15)$ of the blighted ovum (resorption) has two bands with a length of amplification product of $419 \mathrm{bp}$ and $308 \mathrm{bp}$. It seemed that the blighted ovum (resorption) had mostly a single cell population derived from mice species, however, even in small quantities, there were a blighted ovum with two cell populations derived from mice and hamsters species (Figure 5).

Table 4. Fetal morphometry analysis of embryos reconstructed

\begin{tabular}{lll}
\hline Group & Weight \pm SE $(\mathrm{g})$ & $\begin{array}{l}\text { Crown-rump } \\
\text { length }(\mathrm{CR}) \pm \mathrm{SE} \\
(\mathrm{cm})\end{array}$ \\
\hline Normal embryos & $0.166 \pm 0.01^{\mathrm{a}}$ & $1.051 \pm 0.03^{\mathrm{a}}$ \\
Reconstructed embryos & $0.212 \pm 0.08^{\mathrm{b}}$ & $1.283 \pm 0.018^{\mathrm{b}}$ \\
\hline
\end{tabular}

*(a-b, p>0.05) 
Table 5. Placenta and blighted ovum (resorption) morphometry analysis of embryo reconstruction

\begin{tabular}{llccc}
\hline & Group & Weight \pm SE $(\mathrm{g})$ & Diameter \pm SE $(\mathrm{cm})$ & Area \pm SE $\left(\mathrm{cm}^{2}\right)$ \\
\hline Normal embryos & Placenta & $0.120 \pm 0.014$ & $0.763 \pm 0.032$ & $0.482 \pm 0.027$ \\
\multirow{3}{*}{ Reconstructed embryos } & Blighted ovum (resorption) & $0.016 \pm 0.001$ & $0.338 \pm 0.014$ & $0.094 \pm 0.075$ \\
& Placenta & $0.139 \pm 0.011$ & $0.835 \pm 0.022$ & $0.549 \pm 0.034$ \\
& Blighted ovum (resorption) & $0.025 \pm 0.012$ & $0.335 \pm 0.047$ & $0.029 \pm 0.034$ \\
\hline
\end{tabular}

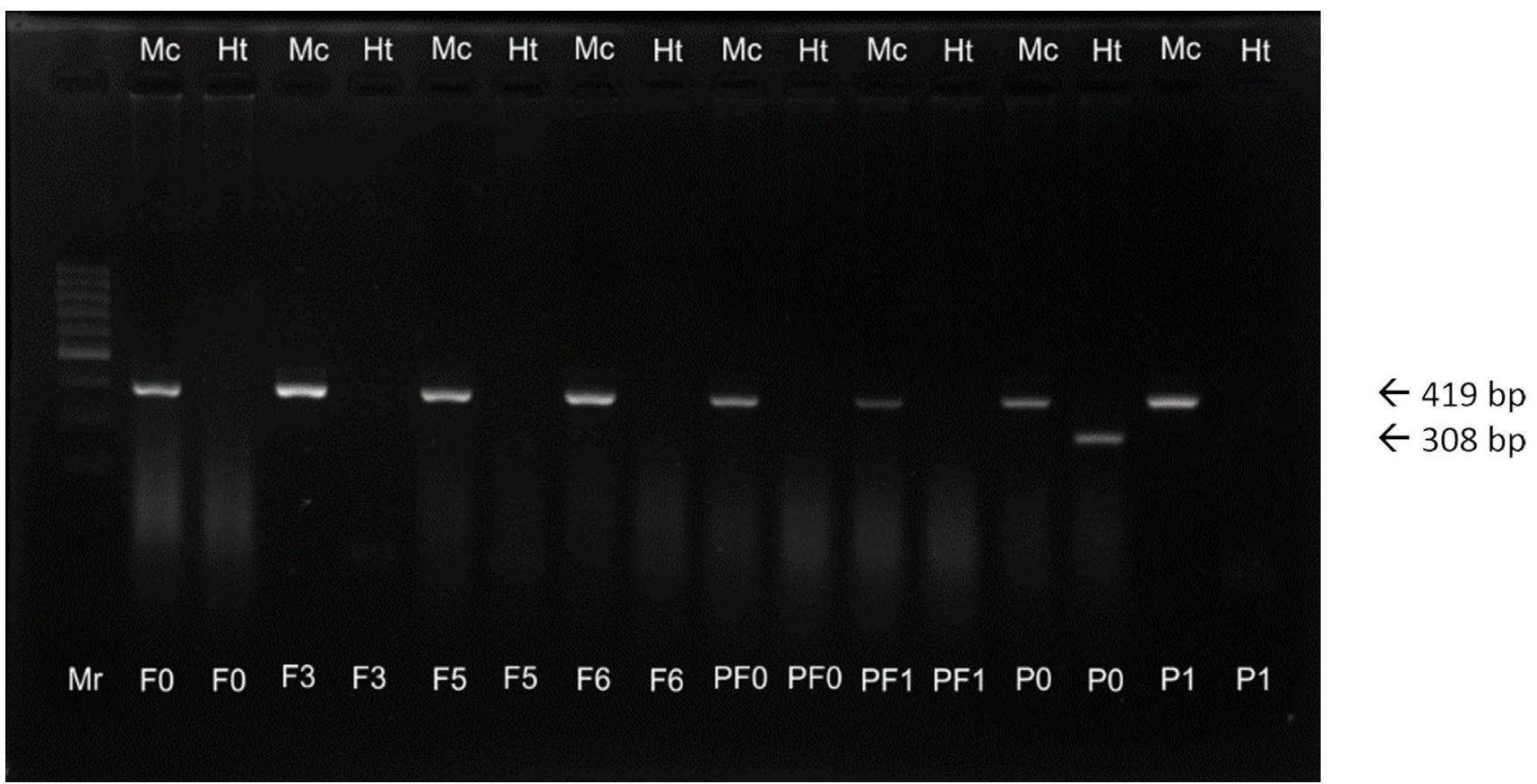

Figure 5. Cytochrome b (Cytb) analysis. fetus (F), placenta (PF), Blighted ovum (resorption) (P), marker (Mr), Mice cytb (Mc), Hamster cytb (Ht)

\section{Discussion}

The result showed that the viability of reconstructed embryos was not affected by the reconstruction procedures using micromanipulator and piezo. The piezo technique in the embryo reconstruction process reduced the trauma on the embryos compared to the conventional methods. The advantages of this technique are that it is fast, consistent, and effective. However, the piezo technique may cause DNA damage inducing the apoptosis process (Yu et al. 2007).

The present study also analysed the viability of donor ICM within the reconstructed embryos. The results of Hoechst staining showed that donor ICM was able to survive for $10 \mathrm{~h}$. This showed that hamster ICM might integrate with the mice embryo and lead to cell communication and thus affect the potential of embryos development and implantation. The results were supported by Loi et al. (2018) explaining that the cattle ICM was able to integrate with the sheep trophoblast for 2 days in vitro, however, ICM subsequently suffered degeneration. This might be due to unfavorable culture environment leading to decrease the development capability of the embryo. In addition, another reason that influenced the development of embryos were the mismatch in the speed of cell development between sheep and cattle (Loi et al. 2018).

The re-expanded reconstructed embryos were transferred into the mothers at day 3.5 after the vaginal plug was found. Vaginal plug is one of markers that shows the mother has been coitus. The coitus affects the regulation of maternal hormone causing the endometrium able to receive the embryos (Yang et al. 2008). After non-surgery transfer method, the results showed that the reconstructed embryos were able to implant. This method is relatively faster and simpler than the surgery method. In addition, embryo transfer using non-surgery methods can reduce the fluctuations in cardiac rhythm and corticosterol levels which is one of the stress biomarkers (Steele 
et al. 2013). The results seemed to show non-surgery methods are able to avoid any physiological disorders caused by the surgery process.

The pregnant mothers were euthanized for fetus collection at day 13.5 of gestation. Developed foetuses and their placentas were found the developed fetuses and its placenta. This indicated that the cell communication occur between the interspecies reconstructed embryos and maternal endometrium. One of the factors that influence the successful implantation of interspecies reconstructed embryos is the genotype matching between the tropectoderm cells and the maternal uterus (Mascetti and Pedersen 2016). The previously study showed that the chimera embryo from Mus musculus and Mus caroli was able to implant (immunological tolerance) (Anderson et al. 1998). However, the chimera embryos have low developmental ability. This might be due to the cell competition in the reconstructed embryos. It was further explained that xenoantigen in trophoblast was able to induce the maternal immune response faster than the alloantigen. The blighted ovum or embryo resorption was also found in this research. Histologically, the embryo resorption experiences apoptosis while the placenta remained intact in the uterus. Several factors may affect including chromosomal abnormalities in the embryos, impaired placenta developmental, nutritional insufficiency, and disruption of immune tolerance between fetus and mothers (Flores et al. 2014).

Morphometric analysis showed that there were significant differences in the weight and length of CR in the fetus of the reconstructed group compared to non-reconstructed group, while the placentas seemed to be similar among both groups. This may be due to the differences in nutrient intake that support fetal development of the embryo reconstructed. Furthermore, Cytb analysis showed that developed fetuses and its placentas have only one cell population derived from mice species. Nevertheless, there was the blighted ovum (resorption) has two cell populations derived from mice and hamsters. These results indicated that even the embryos developed, it were derived from the recipient embryos. We suspect that donor cells started to die during the process of ICM differentiation becoming epiblast. These conditions result in cell competition for growth factors and nutrition. An imbalance of cell competition can cause death in one ICM (Flores et al. 2014). In addition, missmatching cell signaling may occur due to the species evolution. Based on this result, we believe that the increased weight and length of $C R$ in reconstructed group due to the utilization of the final product of the hamster cells autophagy process during the embryos development. Mechanisms begin with the development of donor cells that experienced the signaling mismatch. Tropectoderm cell proliferation is one of the cell communication between trophectoderm (TE)-ICM depended on the mitotic signal secreted by ICM so-called fibroblast growth factor 4 (FGF4). FGF4 secreted by the epiblast post-implantation was influenced by the development of TE (Christodoulou et al. 2019). FGF4 also influence the secretion of bone morphogenetic protein (BMP4) by tropoblast cells. BMP4 serves to stimulate epiblast cell proliferation through paracrine pathway (Murohashi et al. 2010). The mismatch of ligand-receptor interactions and/or affinity difference in molecular adhesion between hamsters and mice resulted in disruption of communication between hamster ICM hamster and mice TE. These conditions might lead to cell competitions including the utilization of histotroph affecting the development of hamster cells. Hamster cells that are experiencing nutritional deficiencies will experience an over-autophagy activation condition. These conditions will result in death in hamster cells (Bialik et al. 2018). The final product autophagy of hamster cells will be used as a source of additional nutrients to support the development of fetal embryo reconstruction.

The differences in signaling systems decrease the activity of cell growth (cell proliferation) and thus stimulate cell competition (Di Gregorio et al. 2016). Furthermore, cell competition is also affected by growth factor or nutritional competitions and lead to autophagy activity in donor cells that ultimately resulted in the donor cell experiencing death. Autophagy products including amino acids and fatty acids can be used as a source of nutrients for the development of embryo cells (Wada et al. 2014).

In general, autophagy is a mechanism to produce energy in the event of a nutrient deficiency condition in the cells. Nevertheless, the autophagy process is also needed for homeostasis during the growth, development and differentiation process (Gong and Kim 2014). Autophagy mechanism plays an important role in implantation, embryogenesis and plasentation processes. The disruption of autophagy process during the embryonic development causes 
inhibition of the tropoblast invasion in the maternal uterus and impairement of the function of the tropoblast (Nakashima et al. 2017). Furthermore, over-activation of autophagy can induce cell death (Gong and Kim 2014).

The successful of interspecies embryo reconstruction in the previous studies (Ovis ariesCapra hircus, Boss taurus-Bos indicus, and Mus musculus-Mus caroli) had a genetic distance of $3 \%$, while the genetic distance between the mice and rat was $20 \%$ (Bozyk et al. 2017). Thus, we tried to analyse the genetic distance between hamster and mice species based on the Cytb sequence data from NCBI. The results showed that the genetic distance between the Phodopus campbelli and Mus musculus was 26.3\%, while in Ovis aries-Capra hircus, Boss taurus-Bos indicus, Mus musculus-Mus caroli, and Mus musculusRattus norvegicus was 13.6, 0.2, 15.6, and 18.6\%, respectively. The high genetic distance between mice and Campbell hamster in this study compared to previous studies might result in a mismatch of the signaling system in supporting the process of hamster cell development in mice embryos. The successful development of interspecies embryo reconstruction is influenced by several things including the speed of cell development and compatibility of cell signaling system (De Los Angeles et al. 2018). Based on the results of the present study, it can be concluded that the interspecies reconstructed embryos were able to develop and to implant. However, it derived only the recipient embryos.

\section{Conflict of Interest}

The authors declare no conflict of interest on this research.

\section{References}

Amstislavsky SYa. 2006. Interspecies embryo and nuclei transfer as a approach to endangered mammalian species conservation. Russ J Dev Biol 37:3-11.

Anderson GB. 1988. Interspecific pregnancy: barriers and prospects. Biol Reprod 38:1-15.

Bialik S et al. 2018. Autophagy-dependent cell death-where, how and why a cell eats itself to death.J Cell Sci 131:112.

Boediono A. 2006. Embryo reconstruction by tranplantation of the donor inner cell mass to the recipient bovine blastocyst. Biotropia 13:69-74.

Bozyk K et al. 2017. Mouse-Rat aggregation chimeras can develop to adulthood. Dev Biol 427:106-120.

Christodoulou $\mathrm{N}$ et al. 2019. Morphogenesis of extraembryonic tissues direct the remodelling of the mouse embryo at implantation. Nat Commun 10:3557.

De Los Angeles et al. 2018. Mini review generating human organ via interspecies chimera formation: advances and barrier. Yale J Biol Med 91:333-342.
Di Gregorio A et al. 2016. Cell competition and its role in the regulation of cell fitness from development to cancer. Dev Cell 38:621-634.

Fatira E et al. 2018. Application of interspecific somatic cell nuclear transfer (iSCNT) in sturgeons and an unexpectedly produced gynogenetic sterlet with homozygous quadruple haploid. Sci Rep 8:59997

Feedman BS. 2018. Hopes and difficulties for blastocyst complementation. Nephron 138:42-47.

Fehilly CB et al. 1984. Interspecific chimaerism between sheep and goat. Nature 307:634-636.

Flores LE et al. 2014. Early detection and staging of spontaneous embryo resorption by ultrasound biomicroscopy in murine pregnancy. Reprod Biol Endocrin 12:1-12.

Garry DJ, Garry MG. 2019. Interspecies chimeras and the generation of humanized organs. Circ Res 124:23-25.

Gong J, Kim GJ. 2014. Review the role of autophagy in the placenta as a regulator of cell death. Clin Exp Reprod Med 41:97-107

Green MA et al. 2009. A device the simple and rapid transcervical transfer of mouse embryos eliminates the need for surgery and potential post-operative complications. Bio Thechniques 47:919-924.

Huang Ket al. 2018. BMI1 enables interpecies chimerism with human pluripotent stem cells. Nat Commun 9:4649.

Loi P et al. 2018. Development to term of sheep embryos reconstructed after inner cell mass/trophoblast exchange. J Reprod Develop 6:187-191.

Mascetti VL, Pedersen RA. 2016. Contribution of mammalian chimeras to pluripotent stem cell research. Cell Stem Cell 19:163-175.

MataHine T et al. 2008. Produksi embryonic stem cells dari inner cell mass blastosis yang diisolasi dengan metode enzimatik dan immunosurgery. J Vet 9:13-19.

Murohashi $M$ et al. 2010. an GFG4-FRS2a-Cdx2 axis in trophoblast stem cells induces Bmp4 to regulate proper growth of easrly mouse embryos. Stem cells 28:113-121.

Nagy A et al. 2003. Manipulating Mouse Embryo In: a Laboratory Manual. 3rd ed. New York: Cold Spring Harbor Laboratory Press.

Nakashima A et al. 2017. Role of autophagy in oocytogenesis, embryogenesis, implantation, and pathophysiology of pre-eclampsia. J Obstet Gynaecol Res 43:633-643.

Nuraini Het al. 2012. The use of cytochrom b gene as a specific marker of the rat meat (Rattus norvegicus) on meat and meat product. Med Peternakan 35:15-20.

Pan X et al. 2013. Development of interspecies nuclear transfer embryos reconstructed eith argali (Ovis ammon) somatic cells and sheep ooplasm. Cell Biol Int 38:211-218.

Rapacz-Leopard A et al. 2014. Major histocompatibility complec I mediates immunological tolerance of the trophoblast during pregnancy and may mediate rejection during parturition. Mediators Inflamm 2014:1-11.

Reese J et al. 2008. Review: the hamster as a model for embryo implantation: insights into a multifaced process. Cell Dev Biol 19:194-203.

Steele KH et al. 2013. Nonsurgical embryo transfer device compared with surgery for embryo transfer in mice. J Am Assoc Lab Anim Sci 52:17-21.

Wada Y et al. 2014. Role of autophagy in embryogenesis. Curr Opn Genet Dev 27:60-66.

Yang JJ et al. 2008. Mating-induced neuroendocrine responses during pseudopregnancy in the female mouse. I Neuroendocrinol 21:30-39.

Yu Yet al. 2007. Piezo-assisted nuclear transfer affects cloning efficiency and may cause apoptosis. Reproduction 133:947-954. 